\title{
Effectiveness of antiplatelet thromboprophylaxis in myeloma patients using immunomodulators in Kurdistan region-Iraq
}

\begin{abstract}
Rezhin N. Rajab*, Firiad Hiwaizi ${ }^{\star}$, Ahmed K. Yassin ${ }^{\star \star}$, Kanar J. Karim* ${ }^{\star \star \star}$, Abid M. Hassan ${ }^{\star \star \star \star}$, Hisham A. Getta $^{\star \star \star \star \star}$, Najmaddin Salih Husen Khoshnaw ${ }^{\star \star \star}$, Sana D. Jalal ${ }^{\star \star \star \star \star}$, Akram M. Mohammed ${ }^{\star \star \star}$, Kawa M. Hasan $^{\star \star}$, Dana A. Abdulla ${ }^{\star \star \star \star \star}$, Ameer I.A. Badi ${ }^{\star \star \star \star \star *}$, Nassir A. S. Al-Allawi ${ }^{\star \star \star \star \star \star}$, Banaz M. Safar ${ }^{\star \star \star}$, Basil K. Abdulla $^{\star \star \star}$, Rawand P. Shamoon ${ }^{\star \star \star \star \star \star \star *}$, Truska A. Amin ${ }^{\star \star \star}$, Zeki A. Mohamed ${ }^{\star \star \star \star}$, Ali I. Mohammed ${ }^{\star \star \star \star *}$, Diveen J. Hussein*, Nawsherwan S. Mohammed ${ }^{\star *}$.

*Department of Hematology, Nanakali Hospital, Erbil, Kurdistan region, Iraq, ${ }^{\star \star}$ Department of of Medicine, College of Medicine, Hawler Medical University, Kurdistan region, Iraq, ${ }^{\star \star \star}$ Department of Hematology, Hewa Cancer Hospital, Sulaymaniyah, Ministory of Health, Kurdistan region, Iraq, ${ }^{* \star \star \star}$ Department of Hematology, Azadi Teaching Hospital, Duhok. Kurdistan region, Iraq, ${ }^{\star \star \star \star \star}$ Department of Pathology, College of Medicine, University of Sulaymaniyah, Kurdistan region, Iraq, ${ }^{* \star \star \star \star \star}$ Department of Hematology, College of Medicine, University of Duhok, Duhok, Kurdistan region, Iraq, ${ }^{\star \star \star \star \star \star \star}$ Ministry of Higher Education, Kurdistan region, Iraq Correspondence:rezhenbotany@gmail.com
\end{abstract}

(Ann Coll Med Mosul 2020; 42 (1):35-41).

Received: $22^{\text {th }}$ Mar. 2020; Accepted: $12^{\text {th }}$ May 2020.

\begin{abstract}
Objective: To evaluate the effect of antiplatelet in preventing thrombosis in multiple myeloma patients treated by immunomodulatory drugs.

Methods: The study was conducted on one hundred seventy-six patients treated in the hematology unit in three centers in the Kurdistan region of Iraq from February 2014 to July 2019, of them, one hundred two males and seventy-four females. Demographic data were obtained from the patient's file, including the type of immunomodulatory drugs, type of antiplatelet, thrombotic events and their site, presence of other comorbidities, and the time onset between diagnosis and beginning of the thrombotic events.

Results: Regardless of the type of therapy in the study sample, $11.1 \%$ who were taking antiplatelet therapy developed a thrombotic attack compared with $46.9 \%$ who were not receiving the anti-platelets treatment. The incidence of the thrombotic attack among those myeloma patients who used immunomodulatory drugs was $9.6 \%$ who were on antiplatelet drugs, which is significantly lower than the rate (52\%) among patients not taking the antiplatelet drugs.

Conclusions: As multiple myeloma is a malignant disease and treatment with immunomodulatory drugs associated with increased risk of thrombosis, the antiplatelet medicine is a useful measure when used as a prophylaxis for preventing thrombosis.
\end{abstract}

Keywords: Multiple myeloma, Thrombosis, Antiplatelet .

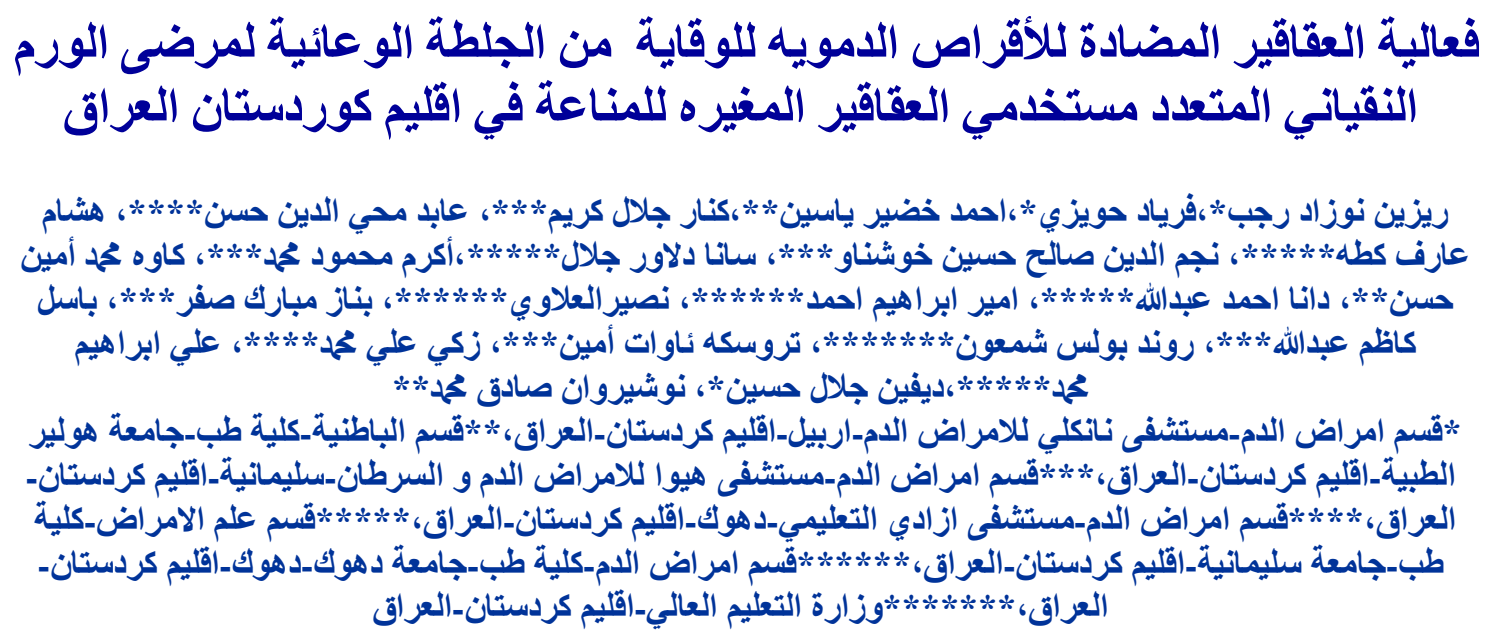


الههاف : تقييم تأثير مضاد الاقر اص في منع تجلط الدم في العديد من مرضى الورم النقياني المتعدد الذين عولجو ا بأدوية مناعية.

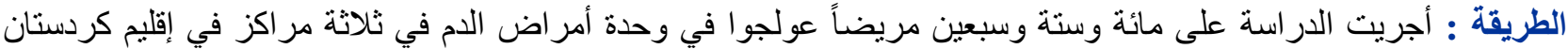

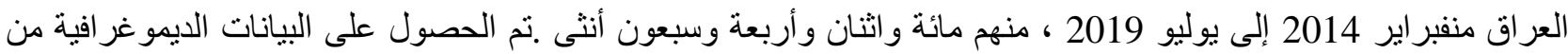

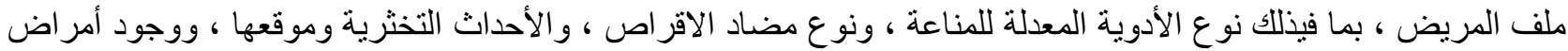

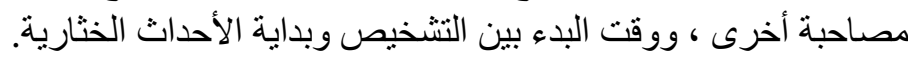
النتائج : بغض النظر عن نوع العلاج في عينة الدراسة ، فإن11.1 ٪ ممن تناولوا العلاج المضاد الاقر اص طوروا نوبة تخثرية

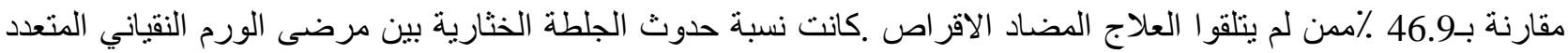

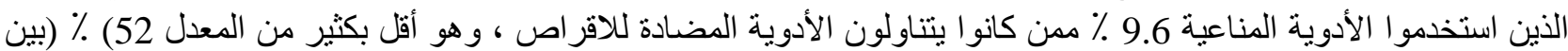

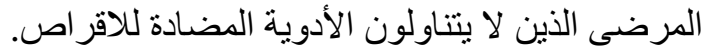

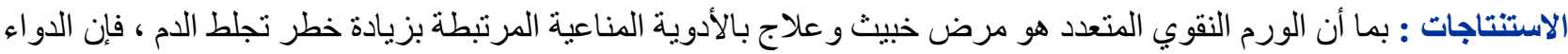

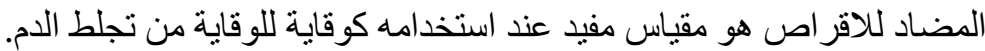

الكلمات المفتاحية : الورم النقوي المتعدد ، تخثر ، مضاد الاقر اص.

\section{INTRODUCTION}

ancer patients are at high risk for thrombosis and pulmonary embolism, especially when known risk factors present, such as the history of venous thromboembolism(VTE), immobilization, dehydration, obesity, old age' and other factors ${ }^{1,2}$. Genetic inheritance and mutations that predispose to thrombosis ${ }^{3}$.

As multiple myeloma is a malignant disease that affects both genders, there is increased incidence of VTE that is highest during the first 3 to 4 months following diagnosis and occurs in approximately 3 to 4 percent of patients receiving either dexamethasone alone or Melphalan Prednisolone, but it is much higher when newer agents are combined with dexamethasone and melphalan such as thalidomide and lenalidomide ${ }^{4,5}$.

Thalidomide is effective in treating patients with multiple myeloma ${ }^{6}$. High-dose dexamethasone, when combined with Lenalidomide, is one of the active and highly accepted strategies for treating patients with relapsed and refractory multiple myeloma ${ }^{7}$, and is similarly effective in patients with newly-diagnosed multiple myeloma ${ }^{8}$. Though, highdose dexamethasone plus lenalidomide is associated with venous thromboembolism rates of $25 \%-67 \%$ in patients with newly-diagnosed $\mathrm{MM}^{8}$.

Prevention of thrombosis has become a significant concern during the treatment of multiple myeloma because of increased use of combined immunomodulatory agent-based therapy 9-12. Prevention of VTE is based on the assessment for known risk factors for VTE such as myelomarelated (hyper viscosity), therapy-related, individual factors (age, history of VTE, inherited thrombophilia, obesity, immobilization, central venous line, infections, surgery and administration of erythropoietin) and comorbidities (acute infection, diabetes mellitus, cardiac or renal disease $)^{13}$.

Because many myeloma patients are taking aspirin for other reasons( such as a cardiac cause or as prophylaxis )and it needs no monitoring while it is easily accessible and cheap, and the recommended dose of aspirin is between 81-325 $\mathrm{mg} /$ day is an option for those myeloma patients with at least one or no risk factor ${ }^{14}$.

Data suggests that aspirin is as effective as warfarin, compared with LMWH except in elder age group were LMWH showed more efficacy than warfarin ${ }^{14}$. Furthermore, when comparing aspirin with other anticoagulant aspirin carries a significantly lower risk of complication than its counterpart anticoagulants. There are some concerns regarding aspirin use, such as there is a chance of aspirin resistance and no specific information regarding effective dose. Nevertheless, aspirin remains a reasonable prophylaxis option in low-risk multiple myeloma patients ${ }^{15}$.

The aim of the study is to evaluate the effectiveness of antiplatelet in preventing thrombosis in a patient with multiple myeloma receiving immunomodulatory drugs.

\section{PATIENTS AND METHODS}

It's a retrospective study that was conducted on one hundred seventy-six symptomatic multiple myeloma patients treated in hematology unit in three centers in Kurdistan region of Iraq(Nanakali hospital at Erbil, Hiwa hospital at Suleimani, and Azadi hospital at Duhok) from February 2014 to July 2019 , of them, one hundred two males and 
seventy-four females. Demographic data were obtained from the patient's file, including the stage of myeloma according to the revised criteria by an international working group in myeloma (reference) type of immunomodulatory drugs, type of antiplatelet (aspirin $81 \mathrm{mg}-325 \mathrm{mg}$ or clopidogrel $75 \mathrm{mg}$ for those who had a gastric problem, thrombotic events and their site, presence of other comorbidity and the time onset between diagnosis and beginning of the thrombotic events.

We recruited all newly diagnosed as well as symptomatic multiple myeloma in cancer-treating centers in the Kurdistan region of Iraq. Those cases with a history of thrombosis prior to the diagnosis of multiple myeloma and those who were on anticoagulation due to other reasons had been excluded.

The only available immunomodulatory medications at the time of the study were (thalidomide and lenalidomide)

\section{Statistical Analysis}

Data were analyzed using the Statistical Package for Social Sciences (SPSS, version 22). Numerical variables were summarized by calculating the means and the standard deviations. Categorical variables were presented in the form of frequencies and proportions. The Chi-square test of association was used to compare proportions. Fisher's exact test was used when the expected count of more than $20 \%$ of the cells of the table was less than 5. A p-value of $\leq 0.05$ was considered statistically significant.

The ethical approval of the present study was obtained from the Kurdistan Board for Medical Specialties (KBMS) in Erbil in 2016.

\section{RESULTS}

The total number of the studied sample was 176 patients who had symptomatic multiple myeloma. Their mean age \pm SD was $60.49 \pm 11.56$ years, the median was 61 years, and the age range was 3589 years. Table 1 shows that the highest proportion of the patients (31.8\%) were in the age group $60-69$ years, and $29 \%$ were in the age group 50-59 years. The ECOG performance stage was $3,4,5$ among $59.1 \%$ of the patients, and ECOG stage $0,1,2$ in $40.9 \%$ of them. About $(54.5 \%)$ of the patients were of stage II, $(29 \%)$ were of stage III, and the rest (16.5\%) were of stage I (Table 1 ).

Antiplatelet was used in 144 (82\%) of cases, of which $16(11.1 \%)$ developed thrombosis while only $32(18 \%)$ were not on antiplatelet agents, of which around 15 (46.9\%) developed thrombotic attack. ( $p$ $<0.001$ )as shown in table 2 .

Patients who were using immunomodulatory drugs seen in Table 3 describes the association of thrombosis and anti-platelet use in each of the treatment groups. Considering patients not taking the immunomodulatory drugs, a significant association was found between anti-platelets intake and the incidence of thrombosis after MM ( $p$ $>0.546$ ). Regarding patients who were on Lenalidomide only, the rate of thrombotic attack was $5.4 \%$ among patients taking the anti-platelets therapy compared with $50 \%$ among patients not taking them $(p=0.014)$. If we consider patients who were using thalidomide, the rate of thrombotic attack among patients taking the antiplatelet drugs was $9.5 \%$ compared with $30.8 \%$ among patients not taking the mentioned drugs $(p=0.056)$. Finally, significant $(p=0.002)$ association was detected between the use of anti-platelets and the incidence of thrombosis after MM among patients who were exposed to lenalidomide and thalidomide sequentially due to toxicity or side effects. The incidence was $21.4 \%$ among patients taking the anti-platelets, compared with $100 \%$ among patients not taking these drugs. A total number of deaths were 33 out of 176 cases, of which 12 of them were due to thrombosis or thrombosis related complications.

Table 1. Basic characteristics of the studied patients.

\begin{tabular}{|l|l|l|}
\hline Age (years) & No. & $(\%)$ \\
\hline$<50$ & 30 & $(17.0)$ \\
\hline $50-59$ & 51 & $(29.0)$ \\
\hline $60-69$ & 56 & $(31.8)$ \\
\hline$\geq 70$ & 39 & $(22.2)$ \\
\hline Gender & & \\
\hline Male & 102 & $(58.0)$ \\
\hline Female & 74 & $(42.0)$ \\
\hline $\begin{array}{l}\text { Performance status according to the Eastern } \\
\text { Cooperative Oncology Group (ECOG) }\end{array}$ \\
\hline Stage 0,1,2 & 72 & $(40.9)$ \\
\hline Stage 3,4,5 & 104 & $(59.1)$ \\
\hline $\begin{array}{l}\text { Stage of disease } \\
\text { (international staging } \\
\text { system) }\end{array}$ & \multicolumn{2}{|l|}{} \\
\hline Stage I & 29 & $(16.5)$ \\
\hline Stage II & 96 & $(54.5)$ \\
\hline Stage III & 51 & $(29.0)$ \\
\hline Total & 176 & $(100.0)$ \\
\hline
\end{tabular}


Table 2. Incidence of thrombotic attack after Multiple Myeloma by antiplatelet intake.

\begin{tabular}{|c|c|c|c|c|c|c|c|}
\hline & & $\begin{array}{l}\text { mbo } \\
\text { MM }\end{array}$ & $c$ at & & & & \\
\hline Use & No & & $\mathrm{Ye}$ & & Tot & & \\
\hline $\begin{array}{l}\text { of } \\
\text { anti- } \\
\text { platel } \\
\text { ets }\end{array}$ & $\begin{array}{l}\mathrm{N} \\
\mathrm{o} .\end{array}$ & $(\%)$ & $\begin{array}{l}\mathrm{N} \\
\mathrm{o} .\end{array}$ & $(\%)$ & $\begin{array}{l}\mathrm{N} \\
\mathrm{o} .\end{array}$ & (\%) & $\mathrm{P}^{*}$ \\
\hline No & 17 & $\begin{array}{l}\text { (53. } \\
1)\end{array}$ & 15 & $\begin{array}{l}(46 . \\
9)\end{array}$ & 32 & $\begin{array}{l}(100 . \\
0)\end{array}$ & \\
\hline Yes & $\begin{array}{l}12 \\
8\end{array}$ & $\begin{array}{l}88 . \\
9)\end{array}$ & 16 & $\begin{array}{l}\text { (11. } \\
1)\end{array}$ & $\begin{array}{l}14 \\
4\end{array}$ & $\begin{array}{l}(100 . \\
0)\end{array}$ & $\begin{array}{l}< \\
0.0 \\
01\end{array}$ \\
\hline Total & $\begin{array}{l}14 \\
7\end{array}$ & $\begin{array}{l}(83 . \\
5)\end{array}$ & 29 & $\begin{array}{l}\text { (16. } \\
5)\end{array}$ & $\begin{array}{l}17 \\
6\end{array}$ & $\begin{array}{l}\text { (100. } \\
\text { 0) }\end{array}$ & \\
\hline
\end{tabular}

*By Chi-square test.
Table 3. Incidence of thrombotic attack after Multiple Myeloma by antiplatelet intake in each of the chemotherapy groups.

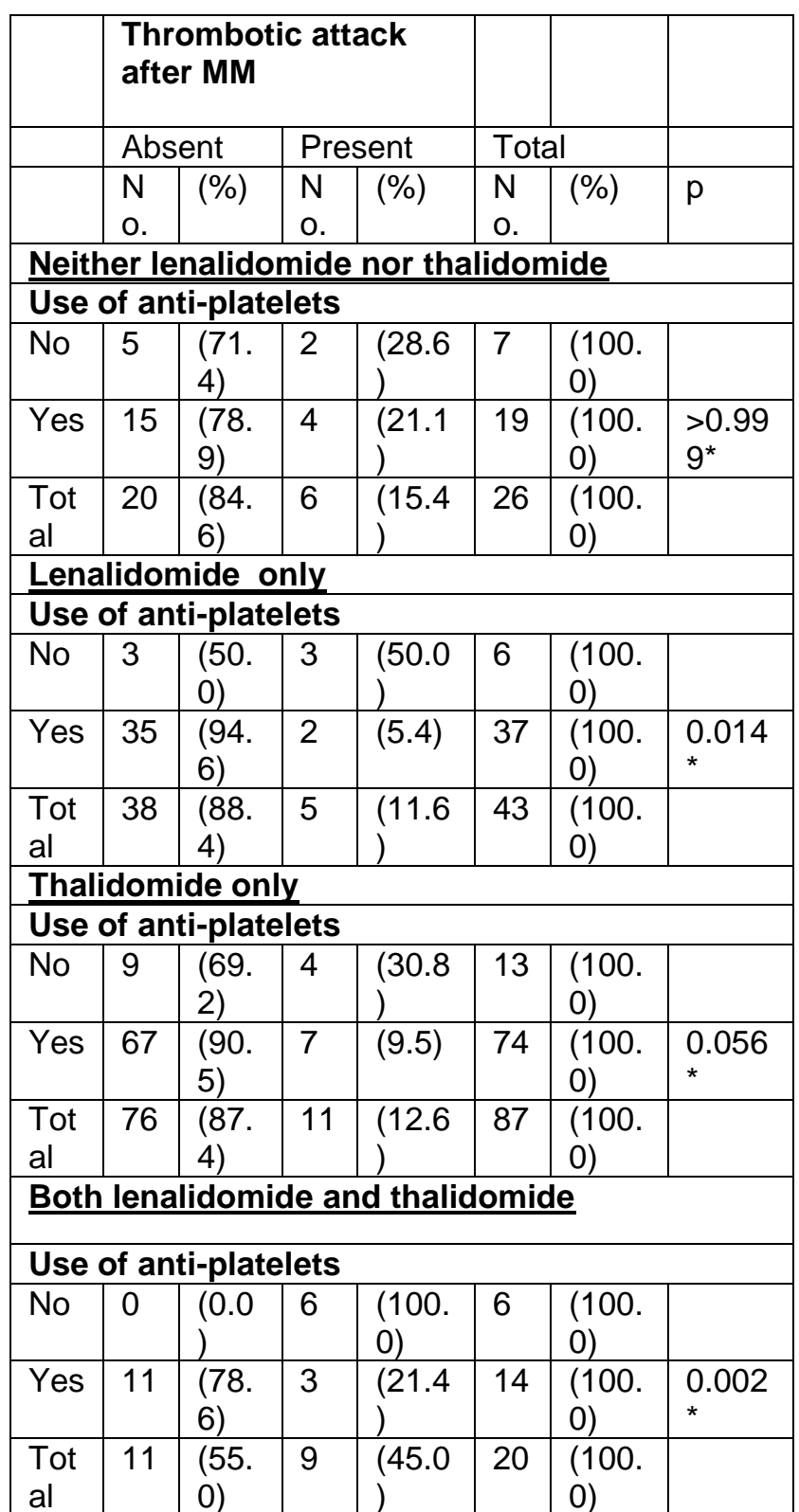

${ }^{*}$ By Fisher's exact test.

In Table 4, we see the incidence of the thrombotic attack among those patients who were on immunomodulatory drugs was $9.6 \%$ in those taking antiplatelet drugs, which is significantly lower than the rate $(52 \%)$ among patients not taking the antiplatelet drugs $(p<0.001)$. 
Table 4. Incidence of thrombotic attack after Multiple Myeloma by antiplatelet intake in patients taking immunomodulatory drugs.

\begin{tabular}{|c|c|c|c|c|c|c|c|}
\hline \multirow{3}{*}{\begin{tabular}{|l|} 
\\
Use \\
of \\
anti- \\
platel \\
ets
\end{tabular}} & \multicolumn{4}{|c|}{$\begin{array}{l}\text { Thrombotic attack } \\
\text { after MM }\end{array}$} & & & \\
\hline & \multicolumn{2}{|c|}{ Absent } & \multicolumn{2}{|c|}{ Present } & \multicolumn{2}{|c|}{ Total } & \\
\hline & $\begin{array}{l}\mathrm{N} \\
\mathrm{O} .\end{array}$ & (\%) & $\begin{array}{l}\mathrm{N} \\
\mathrm{O} .\end{array}$ & (\%) & $\begin{array}{l}\mathrm{N} \\
\mathrm{O} .\end{array}$ & (\%) & $p$ \\
\hline No & 12 & $\begin{array}{l}\text { (48. } \\
0)\end{array}$ & 13 & $\begin{array}{l}\text { (52. } \\
0)\end{array}$ & 25 & $\begin{array}{l}(100 . \\
0)\end{array}$ & \\
\hline Yes & $\begin{array}{l}11 \\
3\end{array}$ & $\begin{array}{l}\text { (90. } \\
4)\end{array}$ & 12 & $\begin{array}{l})^{(9.6} \\
\end{array}$ & $\begin{array}{l}12 \\
5\end{array}$ & $\begin{array}{l}(100 . \\
0)\end{array}$ & $\begin{array}{l}< \\
0.00 \\
1^{*}\end{array}$ \\
\hline Total & $\begin{array}{l}12 \\
5\end{array}$ & $\begin{array}{l}\text { (83. } \\
3)\end{array}$ & 25 & $\begin{array}{l}\text { (16. } \\
7)\end{array}$ & $\begin{array}{l}15 \\
0\end{array}$ & $\begin{array}{l}(100 . \\
0)\end{array}$ & \\
\hline
\end{tabular}

\section{Incidence of thrombotic} attack\%

60.0 52.0

50.0

40.0

30.0

20.0

10.0

0.0

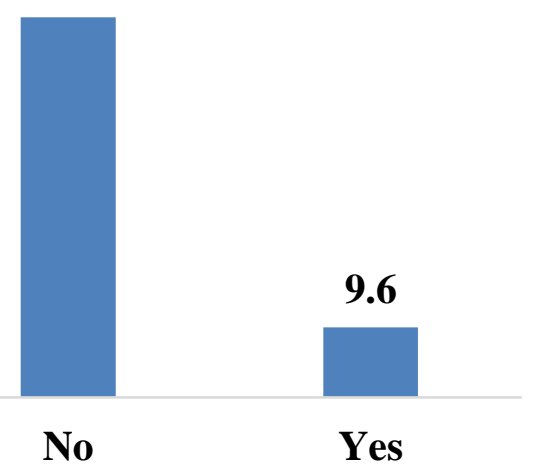

Use of antiplatelets

Figure 1. Incidence of thrombotic attack after Multiple Myeloma by antiplatelet intake in patients taking immune-modulatory drugs.

\section{DISCUSSION}

The development of thrombosis is regarded as a life-threatening complication of cancer patients, especially myeloma population because of increased use of new modalities of treatment like immunomodulators, which can lead to increase inpatient morbidity, treatment discontinuity and requirement of anticoagulation which is additional risk of morbidity, here comes the role of preventing thrombosis as an essential consideration while treating multiple myeloma patients ${ }^{16-18}$.
In our study anti-platelet was given to most patients, the only a small group did not receive it either because of contraindications, patient's will or doctor decision. The thrombotic attacks after diagnosis and treatment of multiple myeloma include (DVT (deep venous thrombosis), PE (pulmonary embolism), stroke, MI (myocardial infarction)) most of them had been confirmed by clinical episode and imaging technique of (ECG, Doppler study, MRI brain, CT angiography). We considered comorbidities in all the patients that might increase the risk of thrombosis, but the results were non-significant.

A recent study has concluded that the rate of hospitalization for thrombosis related complication was double for cancer patients when compared with the general population $(1.8$ vs. 0.8 respectively), and this risk is about eight times higher than general population within the first year of cancer diagnosis but drop down to double then after $^{15,19}$.

The recent trials have found that thromboprophylaxis with aspirin seemed to be effective $^{20}$. The combination of lenalidomidebortezomib dexamethasone with aspirin prophylaxis found hopeful results, with a severe thromboembolism incidence of $5 \%{ }^{21}$.

In our study, we concluded that myeloma patients treated with multi-agent chemotherapy and immunomodulatory are at increased risk of thrombosis. Multivariate analysis, including all patients, revealed that subsequent use of lenalidomide, thalidomide was the most significant risk factor for thrombosis during treatment $(P<$ 0.002).

Similar to our study another study also concluded that, in patients with newly diagnosed multiple myeloma who have no risk for thrombosis, no previous need for antiplatelet or anticoagulation treatment, the use of aspirin as prophylaxis for cases who treated with lenalidomide lead to a lower level of thrombosis when compared with those who didn't receive aspirin with the incidence of thrombosis around $2 \%$ in the aspirin group and there were neither reported case of CVA nor sudden death ${ }^{22}$.

In the study by Antonio et al., The incidence of thrombosis in patients with myeloma without prophylaxis was around $15 \%$ for those who received thalidomide with melphalan and was approximately $20 \%$ for those treated with dexamethasone and thalidomide while the incidence of thrombosis dropped to $6 \%$ through 6 months for those who received prophylaxis aspirin 
${ }^{23,24}$ while in our study patients on thalidomide plus dexamethasone and didn't use aspirin the incidence of thrombosis was $30 \%$ as compared to those who used aspirin $9 \%$ but statistically was non-significant.

\section{CONCLUSION}

Prophylactic antiplatelet is strongly recommended in patients receiving immunomodulatory alone or in combination with chemotherapy in symptomatic myeloma patients.

\section{ACKNOWLEDGMENT}

First and foremost, praises and thanks to God, the Almighty, for His guidance and wisdom as I did my research.

\section{REFERENCE}

1. Sallah S, Wan JY, Nguyen NP. Venous thrombosis in patients with solid tumors: determination of frequency and characteristics. Thrombosis and hemostasis. 2002;87(04):575-9.

2. Swan D, Rocci A, Bradbury C, Thachil J. Venous thromboembolism in multiple myeloma-choice of prophylaxis, the role of direct oral anticoagulants and special considerations. British journal of hematology. 2018 Nov;183(4):538-56.

3. Soare, A.M. and Popa, C. Deficiencies of proteins $\mathrm{C}, \mathrm{S}$ and antithrombin and factor $\mathrm{V}$ Leiden and the risk of ischemic strokes. Journal of medicine and life. 2010, 3(3), p.235.

4. Blom JW, Doggen CJ, Osanto S, Rosendaal FR. Malignancies, prothrombotic mutations, and the risk of venous thrombosis. Jama. 2005 Feb 9;293(6):715-22.

5. Yassin AK. Clinical and Laboratory Profiles of 109 Patients diagnosed as Multiple Myeloma in Erbil City. Journal of the Faculty of Medicine Baghdad. 2013 Jul 1;55(2):121-4.

6. Yassin AK. The survival advantage of adding thalidomide as compared with chemotherapy only in the treatment of symptomatic myeloma in Kurdistan/Iraq. Iraq Journal of Hematology. 2014;3(2):75-84.

7. Weber DM, Chen C, Niesvizky R, Wang M, Belch A, Stadtmauer EA, Siegel D, et al. Lenalidomide plus dexamethasone for relapsed multiple myeloma in North America. New England Journal of Medicine. 2007 Nov 22;357(21):2133-42.
8. Rajkumar SV, Jacobus S, Callander NS, Fonseca R, Vesole DH, Williams ME, et al. Lenalidomide plus high-dose dexamethasone versus lenalidomide plus low-dose dexamethasone as initial therapy for newly diagnosed multiple myeloma: an open-label randomized controlled trial. The lancet oncology. 2010 Jan 1;11(1):29-37.

9. Zonder JA, Crowley J, Hussein MA, Bolejack V, Moore Sr DF, Whittenberger BF, et al. Lenalidomide and high-dose dexamethasone compared with dexamethasone as initial therapy for multiple myeloma: a randomized Southwest Oncology Group trial (S0232). Blood, The Journal of the American Society of Hematology. 2010 Dec 23;116(26):5838-41.

10. Baz R, Li L, Kottke-Marchant K, Srkalovic G, McGowan B, Yiannaki E, et al. The role of aspirin in the prevention of thrombotic complications of thalidomide and anthracyclinebased chemotherapy for multiple myeloma. In Mayo Clinic Proceedings 2005 Dec 1 (Vol. 80, No. 12, pp. 1568-1574). Elsevier.

11. Baz R, Walker E, Karam MA, Choueiri TK, Jawde RA, Bruening $K$, et al. Lenalidomide and pegylated liposomal doxorubicin-based chemotherapy for relapsed or refractory multiple myeloma: safety and efficacy. Annals of oncology. 2006 Dec 1;17(12):1766-71.

12. Niesvizky R, Martínez-Baños $D$, Jalbrzikowski $J$, Christos P, Furst J, De Sancho M, et al. Prophylactic low-dose aspirin is effective antithrombotic therapy for combination treatments of thalidomide or lenalidomide in myeloma. Leukemia \& lymphoma. 2007 Jan $1 ; 48(12): 2330-7$.

13. Palumbo A, Palladino C. Venous and arterial thrombotic risks with thalidomide: evidence and practical guidance. Therapeutic advances in drug safety. 2012 Oct;3(5):255-66.

14. Palumbo A, Cavo M, Bringhen S, Zamagni E, Romano A, Patriarca F, et al. Aspirin, warfarin, or enoxaparin thromboprophylaxis in patients with multiple myeloma treated with thalidomide: a phase III, open-label, randomized trial.

15. Cronin-Fenton DP, Søndergaard F, Pedersen LA, Fryzek JP, Cetin K, Acquavella J, et al. Hospitalisation for venous thromboembolism in cancer patients and the general population: a population-based cohort study in Denmark, 
1997-2006. British journal of cancer. 2010 Sep;103(7):947-53.

16. Fotiou D, Gavriatopoulou M, Terpos E. Multiple Myeloma and Thrombosis: Prophylaxis and Risk Prediction Tools. Cancers. 2020 Jan;12(1):191.

17. Sanfilippo KM, Luo S, Wang TF, Fiala M, Schoen M, Wildes TM, et al. Predicting venous thromboembolism in multiple myeloma: development and validation of the IMPEDE VTE score. American journal of hematology. 2019 Nov;94(11):1176-84.

18. Li $A$, Wu $Q$, Luo $S$, Warnick GS, Zakai NA, Libby EN, et al. Derivation and Validation of a Risk Assessment Model for Immunomodulatory Drug-Associated Thrombosis Among Patients With Multiple Myeloma. Journal of the National Comprehensive Cancer Network. 2019 Jul 1;17(7):840-7.

19. Bradbury CA, Jenner MW, Striha A, Cook G, Pawlyn C, Jones JR, et al. Thrombotic events in patients with myeloma treated with immunomodulatory drugs; results of the Myeloma XI study. Blood. 2017 Dec 7;130(Supplement 1):553-.

20. Palumbo A, Falco $P$, Corradini $P$, Falcone $A$, Di Raimondo F, Giuliani N, et al. Melphalan, prednisone, and lenalidomide treatment for newly diagnosed myeloma: a report from the GIMEMA-Italian Multiple Myeloma Network. J Clin Oncol. 2007 Oct 1; 25(28):4459-65.

21. Richardson PG, Weller E, Lonial S, Jakubowiak AJ, Jagannath $S$, Raje NS, et al. Lenalidomide, bortezomib, and dexamethasone combination therapy in patients with newly diagnosed multiple myeloma. Blood, the Journal of the American Society of Hematology. 2010 Aug 5; 116(5):679-86.

22. Larocca A, Cavallo F, Bringhen $S$, Di Raimondo F, Falanga A, Evangelista $A$, et al. Aspirin or enoxaparin thromboprophylaxis for patients with newly diagnosed multiple myeloma treated with lenalidomide. Blood. 2012 Jan 26; 119(4):933-9.

23. Palumbo A, Cavo M, Bringhen $S$, Zamagni $E$, Romano A, Patriarca $F$, et al. Aspirin, warfarin, or enoxaparin thromboprophylaxis in patients with multiple myeloma treated with thalidomide: a phase III, open-label, randomized trial.
24. Al-Ani F, Bermejo JM, Mateos MV, Louzada M. Thromboprophylaxis in multiple myeloma patients treated with lenalidomide-A systematic review. Thrombosis research. 2016 May 1; 141:84-90. 